\title{
Current Safety Culture among Laboratory Users of the Faculty of Engineering in Universiti Putra Malaysia
}

\author{
Siti Aslina Hussain ${ }^{1,2 *}$, Michelle Anne Dison ${ }^{1,2}$ \\ ${ }^{1}$ Department of Chemical and Environmental Engineering, Faculty of Engineering, Universiti Putra \\ Malaysia, 43400 Serdang, Selangor, Malaysia
}

${ }^{2}$ Safety Engineering Interest Group (SEIG), Department of Chemical and Environmental Engineering, Faculty of Engineering, Universiti Putra Malaysia, 43400 UPM Serdang, Selangor, Malaysia

*Corresponding author: aslina@upm.edu.my

\section{Article History}

Received: September 09, 2020 Received in revised form: October 30, 2020 Accepted: November 15, 2020 Published Online: December 312020

\begin{abstract}
Accidents involving higher learning institutes laboratories are no longer a worldwide issue. There is a huge gap between how safety is practiced in industry compared to how it is practiced in research laboratories, especially in an academic setting. For effective implementation of the safety management system, it is necessary to have a strong and positive safety culture throughout the organization. The investigation to the safety culture (SC) practices level and performances among laboratory's users in the Faculty of Engineering, Universiti Putra Malaysia will be assessed, evaluated and recommended some of the improvement towards SC in UPM. The assessment is done through the distribution of safety culture questionnaire adapted from Hudson's safety culture element and a publication by American Chemical Society and the results will be based on rating distribution. The safety culture survey resulted in an overall score of $\mu=3.98(\mu<4.0)$ which indicates that the level of safety culture among laboratory users are moderate and less proactive. Observation from the audit evaluation suggested that there are still room of improvement for the safety performance. It is deduced from this study that the safety culture and safety performance are inter-related to each other. Therefore, to achieve higher safety performance, one needs to have an improvement in safety culture change in their organization.
\end{abstract}

Keywords: Safety Culture; Academic Laboratories; Safety Performance; Safety Management System; Human Factor; Organization

\subsection{INTRODUCTION}

\subsection{Accident Cases in Academic Laboratories}

Academic laboratories in universities and college are used as a platform for students to learn new skills and verify scientific theories [1]. There are times that lab work can be excruciating because of the long hours spent for an experiment. To ensure that students are able to acquire the essential skills and assist researcher to obtain meaningful lab results, it is crucial for the faculty to pay close attention to the safety issues in the experimental laboratories, in addition to emphasizing instruction or issues of experimental laboratories management [1]. Incidents involving higher institutions laboratories are no longer a peculiar situation or issue. Though the number of incidents and accidents involving academic institutions are higher as compared to industrial laboratory, the reason why these incidents are less documented and reported is mainly because their impact and damages are generally confined within the institution [2].

Many perceive that it is safe to be working on a research in an academic laboratory. However, this perception is somehow contradicting to the fact that many mishaps have been reported happened in academic laboratory [1]. Wu et al. reported that the reason accidents are prone to happen in the academic laboratory is due to the students' at-risk behavior while working in the lab. Table 1 shows some of the situation associated with laboratory accidents happened across the world and their respective root cause that was reported in literature. 
Table 1 Past accidents happened in academic laboratories

\begin{tabular}{|c|c|c|c|}
\hline Year & Location & Accident Scenario & Root Cause \\
\hline Oct 26, 2019 & $\begin{array}{l}\text { Technion - Israel } \\
\text { Institute of Technology } \\
\text { [27] }\end{array}$ & $\begin{array}{l}\text { Emeritus Professor Elazar } \\
\text { Gutmanas succumbed to a severe } \\
\text { injury sustained in lab explosion } \\
\text { involving hydrogen research at the } \\
\text { Department of Materials Science } \\
\text { and Engineering. }\end{array}$ & $\begin{array}{l}\text { Root cause is still unknown. } \\
\text { There is no investigation report } \\
\text { published online. }\end{array}$ \\
\hline Dec 6, 2018 & $\begin{array}{l}\text { Laboratory for } \\
\text { Hypersonic and Shock } \\
\text { Wave Research, Indian } \\
\text { Institute of Science, } \\
\text { Bengaluru [9] }\end{array}$ & $\begin{array}{l}\text { Manoj Kumar, a researcher died in } \\
\text { a blast due to a leak in a hydrogen } \\
\text { cylinder while } 3 \text { other researchers } \\
\text { were injured. }\end{array}$ & $\begin{array}{l}\text { Breach in a lab security protocol } \\
\text { Students and researchers at IISc do } \\
\text { not go through a mandatory safety } \\
\text { training }\end{array}$ \\
\hline $\begin{array}{l}\text { March 16, } \\
2016\end{array}$ & $\begin{array}{l}\text { University of Hawaii } \\
(\mathrm{UH}), \text { Manoa [8] }\end{array}$ & $\begin{array}{l}\text { A post doctorate, Thea Ekins- } \\
\text { Coward lose her arms in an } \\
\text { explosion resulted from a static } \\
\text { electricity charge that caused the } \\
\text { ignition of a tank containing highly } \\
\text { flammable of pressurized hydrogen, } \\
\text { oxygen, and carbon dioxide. }\end{array}$ & \begin{tabular}{|l|} 
- \\
experisk assessment done for a new \\
with highly hazardous materials \\
Deficiencies in institution's \\
approach to laboratory safety, \\
especially the lack of safety culture. \\
Insufficient training in hazard \\
recognition and risk mitigation \\
Deficiencies in laboratory \\
inspection program \\
Ineffective chemical hygiene plan \\
Inadequate standard operating \\
procedure
\end{tabular} \\
\hline June 17, 2014 & $\begin{array}{l}\text { Chemistry Lab, } \\
\text { University of Minnesota } \\
\text { [7] }\end{array}$ & $\begin{array}{l}\text { Walter Partlo, a graduate student } \\
\text { was injured due to explosion when } \\
\text { he was making trimethylsilyl azide } \\
\text { using sodium azide. }\end{array}$ & $\begin{array}{l}\text { - Lack of hazard awareness } \\
\text { Insufficient recognition of the } \\
\text { reaction's hazards }\end{array}$ \\
\hline April 14, 2011 & $\begin{array}{l}\text { Chemistry Laboratory, } \\
\text { Yale University [6] }\end{array}$ & $\begin{array}{l}\text { Michele Dufault, 22, a senior } \\
\text { undergraduate science student died } \\
\text { from accidental asphyxia by neck } \\
\text { compression. Her hair was caught } \\
\text { in a machine's rotating drive and } \\
\text { dragged her onto it while using a } \\
\text { fast-spinning lathe in the student } \\
\text { machine shop. }\end{array}$ & $\begin{array}{l}\text { - No emergency shut-off switch nor a } \\
\text { part known as a guard that shields } \\
\text { the person working at the machine. } \\
\text { - Safety deficiencies in term of } \\
\text { missing warning signs } \\
\text { - Inadequate record keeping } \\
\text { - Working alone in the lab }\end{array}$ \\
\hline $\begin{array}{l}\text { January 7, } \\
2010\end{array}$ & $\begin{array}{l}\text { Texas Tech Laboratory } \\
{[5]}\end{array}$ & $\begin{array}{l}\text { Preston Brown, a senior graduate } \\
\text { student was severely injured due to } \\
\text { explosion while conducting an } \\
\text { experiment. He loses three fingers, } \\
\text { perforation of his eye, and cuts and } \\
\text { burns on other parts of his body. }\end{array}$ & $\begin{array}{l}\text { No formal training with the } \\
\text { material/hazards associated with the } \\
\text { experiment. } \\
\text { Not wearing personal protection } \\
\text { equipment }\end{array}$ \\
\hline Dec 29, 2008 & $\begin{array}{l}\text { University of California, } \\
\text { Los Angeles [4] }\end{array}$ & $\begin{array}{l}\text { Sheharbano Sangji, a research } \\
\text { assistant died from injuries } \\
\text { sustained in a chemical fire. }\end{array}$ & $\begin{array}{ll}\text { - } & \text { Lack of training } \\
\text { - } & \text { Failure to document training } \\
\text { - Failing to correct unsafe laboratory } \\
\text { conditions and work practices }\end{array}$ \\
\hline
\end{tabular}

The scope of operations at universities is often increasing in complexity due to further collaboration with researchers at other institutions [10]. The academic world continues to be the hub for experimental testing where the concept of free study leads to making it a risky environment. Langerman had reviewed 94 lab incidents investigation led by the Chemical Safety and Hazard Investigation Board (CSB) and he concluded that the academic laboratories are an unsafe area for work and study. His conclusion was supported by Michael J. Halligan, an Associate Director of the Environmental Health and Safety at the University of Utah with the facts that there are more accidents happened in academic laboratories as compared to industrial laboratories [11]. On top of that, James Kaufman has urged that the accidents rate in academic laboratories are more common than the accidents rate in industrial laboratories [12,13].

\subsection{The Need to Improve Safety Culture in Academic Laboratories}

Recent accidents underscore the general observation that adherence to best safety practices is insufficient in academic laboratories and that the requisite attitudes, awareness, and ethics about safety issues - the "culture of safety"- are not sufficiently instilled among the faculty and students. To improve the culture of safety for all academic research, top management involvement is crucial as a support system. Safety culture originates from ethical, moral, and practical 
consideration, rather than regulatory requirements. It reflects the actions, attitudes, and behaviors of its members concerning safety in which these members include the managers, supervisors, and employees within the industrial and governmental communities, whereas within the academic community, the members include administration, faculty, staff, and students [14].

Experts agree that safety culture is the fundamental element in preventing accidents and incidents. At the same time, to achieve an effective safety culture, promotional activities which involves promoting and enhancing the safety culture through training, personnel competencies, communication throughout workforce, and hazard or risk awareness should be included to instill and reinforce the culture. The level of safety behavior at workplace is greatly influenced by the management commitment to safety as different level and types of management within an organization will have an impact on the attitude, perception, and behaviors of the workforce [15]. Both management and the workforce commitment are crucial to have safe practices at workplace. Managers should create a positive "safety culture" and "an open learning atmosphere" to be able to have an open discussion on mistakes, errors, and near-misses without the fear of being blame and recrimination [16].

Safety culture was first being introduced by the International Atomic Energy Agency (IAEA) in 1986 after the Chernobyl disaster took place [17]. Many researchers have also had their own definition of the term safety culture and most of the definitions are relatively similar in term of their belief and perspective in relation to safety. According to Kennedy and Kirwan (1998), safety culture is a sub-element of the overall organizational culture [18]. Hale (2000) defined safety culture as "the attitude, beliefs, and perceptions shared by natural groups as defining norms and values, which determine how they act and react in relation to risks and risk control systems" [19]. Mohamed (2003) perceives safety culture as a sub-facet of organizational culture, which affects workers' attitudes and behavior in relation to an organization's on-going safety performance [20].

Various past studies have concluded several factors to have influence in creating a conducive workplace to a positive safety culture. The key factors are management [21], individual and behavioral workforce [22], and rules and procedures [23]. Studies done by Choudhry et al. (2007), Wiegmann et al. (2004), Mearns et al. (2003), and Cooper (2000) mentioned that management commitment possessed the strongest influence over safety culture as an outcome [30,28,29,22]. Thus, management plays an important role to ensure that their employees understand and fully aware of the importance of their responsibilities for safety as well as to ensure that their employees are continually motivated to achieve a high level of personal performance [24].

To improve and strengthen safety level, the right approach in leadership is crucial because it is the leader's main role in reducing exposure and creates a climate and culture that is favorable for safety. The leaders are the key person in driving and ensuring that the safety culture in their organization is effective, which in turn drives the behaviors of the people within the organization. The management can show their support in developing safety culture at work by providing resources, safety personnel, safety training and by doing incident investigations.

The objective of this study is to assess the level of safety culture (SC) practices among laboratory's users and to propose recommendations for improvements towards SC in UPM. The scopes of this study are only confined and focus on six elements of safety culture derived from the Energy Institute and a report on safety culture in academic institutes published by the American Chemical Society. To execute this study, a set of questionnaires was developed and distributed to the members of the faculty which include undergraduate students (UG), postgraduate students (PG), lecturers (L), assistant engineers (AE), and researchers (R) through physical and online distribution via Google form. Section 2.0 describes the methodology used in this study and Section 3.0 presents the results and discussion of this study.

\subsection{METHODOLOGY}

A survey on the assessment of safety culture practices was conducted among laboratory users' in the Faculty of Engineering located at Universiti Putra Malaysia, Selangor. Six elements of safety culture adapted from the Energy Institute and a report on safety culture in academic institutes published by the American Chemical Society as depicted in Table 2.

Table 2 Safety Culture Element Adapted from Energy Institute and American Chemical Society [25,14]

\begin{tabular}{|l|l|}
\hline Element 1 & Leadership and Commitment \\
\hline Element 2 & Hazard and Effect Management \\
\hline Element 3 & Promoting and Communicating Safety \\
\hline Element 4 & Competency and Training \\
\hline Element 5 & Safety Implementation and Monitoring \\
\hline
\end{tabular}




\begin{tabular}{|l|l|}
\hline Element 6 & Safety Ethic and Awareness \\
\hline
\end{tabular}

\subsection{Design and Structure of Survey Questionnaire}

This questionnaire was designed based on Hudson's safety culture elements and a publication by American Chemical Society entitled "Creating Safety Cultures in Academic Institutions. The questionnaire was divided into two sections, Section A and Section B. The first section focuses on demographic question to obtain better insight into the respondents' background and information. This includes the gender of respondents, age of respondents, job position, type of laboratories their work station located (either in a teaching lab or in a research lab), the departments of the respondents, as well as the time duration they spend in the laboratories within a week The second section focuses on the safety culture survey which includes the six elements of safety culture in academic institutions.

In the second section of the questionnaire, which is Section B, there will be several safety dimensions for each of the safety element listed in Table 2 and the respondents are requested to express their agreement or disagreement on a fivedegree Likert scale. An example of the Section B questions used for this study is shown in Figure 1.

\begin{tabular}{|c|c|c|c|c|c|c|c|c|c|}
\hline \multicolumn{8}{|c|}{ Section B: Safety Culture Survey } & & \\
\hline & 1 & 2 & 3 & 4 & \multicolumn{3}{|c|}{5} & & \\
\hline & $\begin{array}{l}\text { Strongly } \\
\text { Disagree }\end{array}$ & Disagree & Moderate & Agree & \multicolumn{3}{|c|}{ Strongly Agree } & & \\
\hline No. & \multicolumn{4}{|c|}{ Survey Questionnaire } & 1 & 2 & 3 & 4 & 5 \\
\hline \multicolumn{10}{|c|}{ Element 1: Leadership and Commitment } \\
\hline 1 & \multicolumn{4}{|c|}{$\begin{array}{l}\text { If I see a person in my lab doing something unsafe, I feel comfortable } \\
\text { addressing the issue directly with him/her. }\end{array}$} & & & & & \\
\hline 2 & \multicolumn{4}{|c|}{ My lab colleagues exert a strong peer pressure on me to work safely. } & & & & & \\
\hline 3 & \multicolumn{4}{|c|}{$\begin{array}{l}\text { Students are educated in the principles of safety throughout the } \\
\text { curriculum. }\end{array}$} & & & & & \\
\hline 4 & \multicolumn{4}{|c|}{$\begin{array}{l}\text { Students continuously learn about safety during structured laboratory } \\
\text { sessions. }\end{array}$} & & & & & \\
\hline 5 & \multicolumn{4}{|c|}{$\begin{array}{l}\text { Faculty, staff, and postdoctoral scholars, who teach or oversee research in } \\
\text { laboratories, are educated and trained in safety skills. }\end{array}$} & & & & & \\
\hline 6 & \multicolumn{4}{|c|}{$\begin{array}{l}\text { Everyone in the lab has a high level of commitment in practicing safe } \\
\text { work procedure. }\end{array}$} & & & & & \\
\hline 7 & \multicolumn{4}{|c|}{$\begin{array}{l}\text { Everyone working in the lab has a high level of care for the safety of } \\
\text { other team members. }\end{array}$} & & & & & \\
\hline 8 & \multicolumn{4}{|c|}{ I alert my colleagues who act contrary to work safety rules. } & & & & & \\
\hline 9 & \multicolumn{4}{|c|}{ My colleagues point out each other's deficiencies in work safety. } & & & & & \\
\hline
\end{tabular}

Figure 1 Example of Safety Culture Survey Questions

\subsection{Site Selection}

The questionnaire was distributed to all personnel in the laboratories ranging from undergraduate and postgraduate students, researchers, lecturers, assistant engineers, and engineers. There were two types of laboratories involved in this study: teaching lab and research lab.

The hardcopy questionnaires were distributed randomly by the authors herself to students and employees within the compound of the Faculty of Engineering Apart from that, the questionnaire were also distributed online via Google form to 171 employees from eight departments; Department of Aerospace Engineering, Department of Civil Engineering, 
Department of Biological and Agricultural Engineering, Department of Electrical and Electronic Engineering, Department of Chemical and Environmental Engineering, Department of Computer and Communication System Engineering, Department of Mechanical and Manufacturing Engineering, as well as Department of Process and Food Engineering.

In the questionnaire, the respondents were asked to complete a specific, standardized questionnaire to obtain their perception on the specified safety related dimensions. The study focused on six (6) elements which contributes to the safety culture which includes leadership and commitment, hazards and effect management, promoting and communicating safety, competency and training, safety implementation and monitoring, as well as safety ethic and awareness. This approach focuses on assessing the organization's current state of maturity on their safety culture by giving it a ranking on a predefined 'culture maturity ladder' that shows different levels or stages of cultural maturity.

\subsection{Data Analysis}

The data analysis method was performed after the questionnaire data were collected. All the data obtained from the questionnaire were assembled, then organized and summarized to obtain an appropriate and suitable results of the collected data. Data will be analyzed using statistical analysis through SPSS software. In this study, the rating for each safety dimension will be calculated to determine the overall mean (' $\mu$ ' value) for the main element. Since the questionnaire is in a 5-point Likert's type scale distribution ranging from $1=$ strongly disagree, $2=$ disagree, $3=$ moderate, $4=$ agree, $5=$ strongly agree in which it correspond to the 5-scale safety culture ladder by Patrick Hudson [26] ranging from 1 = Pathological, 2 = Reactive, 3 = Calculative, 4 = Proactive, and $5=$ Generative as illustrated in Figure 2.

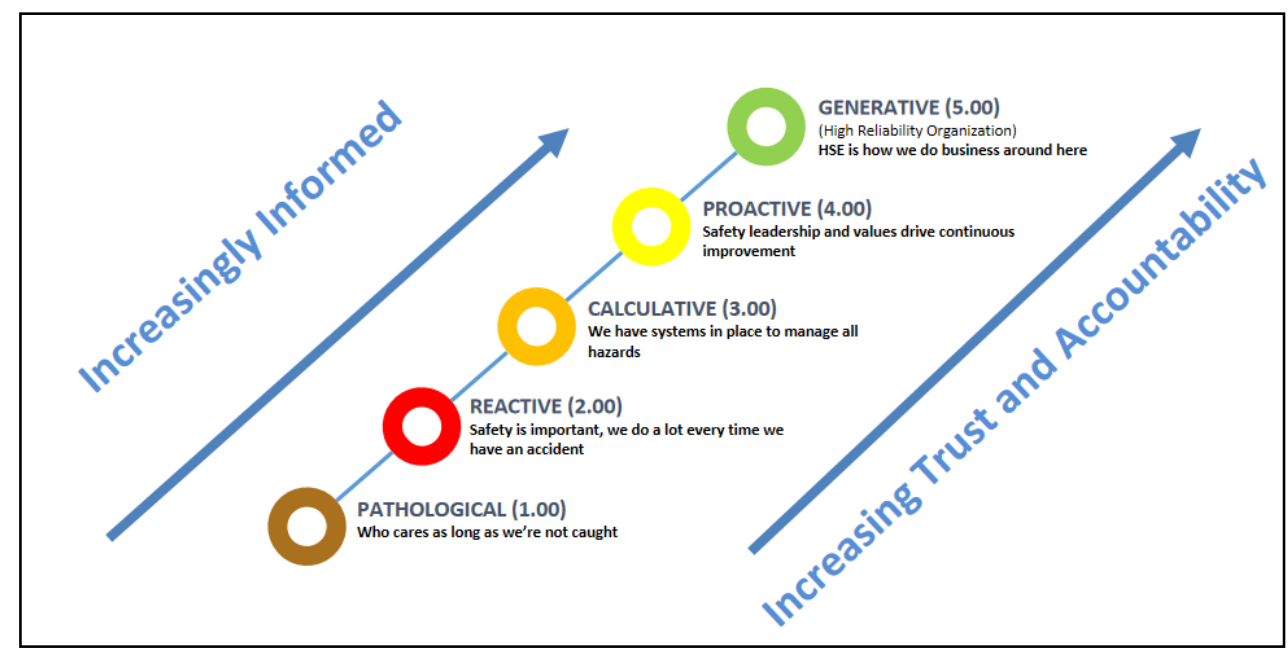

Figure 2 Hudson's Safety Culture Ladder [26]

After determining the rating of each safety dimension, the overall mean ( $\mu$-value) is calculated by dividing the summation of overall rating of the element with the total number of safety dimensions in each element as shown in equation 1.

$$
\mu=\frac{\sum \text { rating of each safety dimension }}{\sum \text { total safety dimension in each element }}
$$

The acceptable mean range would be in between 4.0 and $5.0(4.0 \leq \mu \leq 5.0)$ which accounts for proactive and generative culture. Mean value of below $4.0(\mu<4.0)$ is considered low and this shall account for pathological, reactive, and calculative culture. Recommendation shall be proposed for the improvement of safety culture practices throughout the organization.

\subsection{RESULTS}

The questionnaires were distributed to all 8 engineering departments, with a total of 31 respondents in which $67.7 \%$ were undergraduate students (UG), $12.9 \%$ of them were lecturers (L), 9.7\% were assistant engineers (AE) while $6.5 \%$ were postgraduate students (PG) and 3.2\% were researcher (R). On the first round of physical distribution, a total of 50 set of questionnaires were distributed randomly to students and employees within the compound of the Faculty of Engineering 
and there were 25 respondents answered. Second round of physical distribution was hampered due to pandemic Covid19 restrictions movement. Nevertheless, the questionnaire were also distributed online via Google form to 171 employees from eight departments; Department of Aerospace Engineering, Department of Civil Engineering, Department of Biological and Agricultural Engineering, Department of Electrical and Electronic Engineering, Department of Chemical and Environmental Engineering, Department of Computer and Communication System Engineering, Department of Mechanical and Manufacturing Engineering, as well as Department of Process and Food Engineering. From the online form, there were 6 respondents returned their feedback. As overall, the response rate of this study is $53.5 \%$.

3.1

\section{Element 1-Leadership and Commitment}

Figure 3 shows the rating distribution and safety culture stage for Leadership and Commitment in Element 1. Based on the bar chart illustrated in Figure 3, majority of the safety dimensions score rating above 4.0 which shows that the organization is in the proactive stage in term of leadership and commitment. However, only one safety dimension shows a value of 3.58 which is in the calculative stage. This is corresponding to the $13 \%$ of respondent percentage in Figure 4 who disagree that their laboratory colleagues are exerting peer pressure on them to work safely. One of the ways to improve this is to implement stringent rules or code of conduct in the laboratories to avoid students or laboratories users from violating. As overall, the safety dimension for leadership and commitment scores a mean value of $\mu=4.06$ which falls under proactive culture.

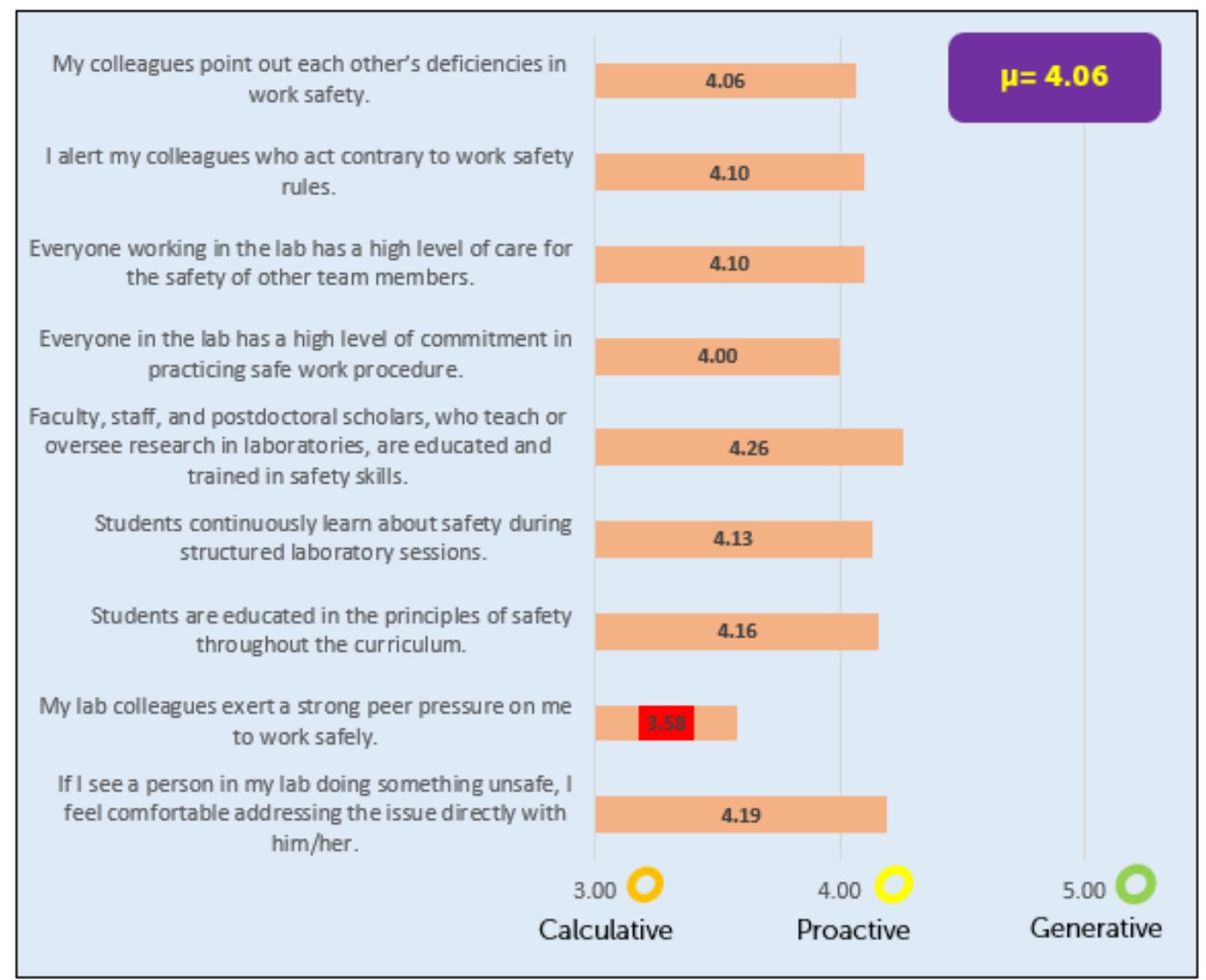

Figure 3 Rating Distribution and Safety Culture Stage for Leadership and Commitment in Element 1 
My colleagues point out each other's deficiencies in work safety.

I alert my colleagues who act contrary to work safety rules.

Everyone working in the lab has a high level of care for the safety of other team members.

Everyone in the lab has a high level of commitment in practicing safe work procedure.

Faculty, staff, and postdoctoral scholars, who teach or oversee research in laboratories, are educated and...

Students continuously learn about safety during structured laboratory sessions.

Students are educated in the principles of safety throughout the curriculum.

My lab colleagues exert a strong peer pressure on me to work safely.

If I see a person in my lab doing something unsafe, I feel comfortable addressing the issue directly with him/her.

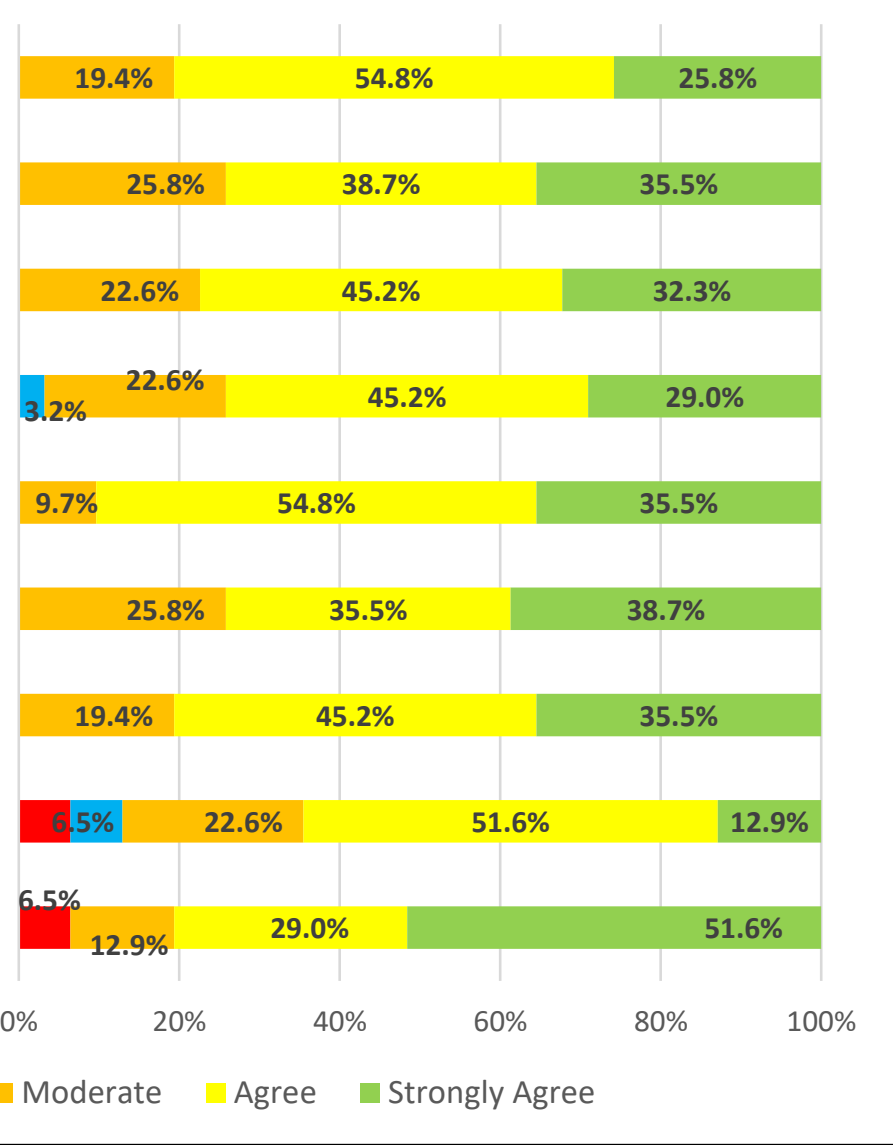

Figure 4 Respondent for Leadership and Commitment in Element 1

\section{2} Element 2-Hazard and Effect Management Process

Hazard and Effect Management Process (HEMP) is a structured methodology for the identification of hazards and assessment of the associated risks, and development of the management system required in terms of barriers to reduce the risks to As Low As Reasonably Practicable (ALARP). HEMP process is an analysis technique that reviews the identified hazards and uses a Risk Assessment Matrix to rank the risks based on consequence and likelihood. Figure 5 shows the rating distribution and safety culture stage for Hazard and Effect Management Process in Element 2. Majority of the safety dimensions score rating below 4.0 which shows that the organization is in the calculative stage in term of the application of HEMP process.

Out of the seven (7) safety dimensions in Element 2, three (3) safety dimensions is associated with the application of HEMP process which is shown in Table 3. Based on the survey results, $16.1 \%$ of the respondents did not do risk assessment before conducting any laboratory work and the same percentage of respondent neither agree nor disagree on conducting risk assessment before performing laboratory work. On the other hand, $6.5 \%$ of the respondents do not conduct hazard analysis before conducting their research, whereas $38.7 \%$ of the respondents neither agree nor disagree. Results also show that $16.1 \%$ of the respondents did not routinely identify and manage risk as part of their work processes during group work, whereas the same percentage respondent neither agree nor disagree. This result shows that there is a deficiency in the areas of hazard identification and risk assessment and management among laboratories users.

Table 3 Respondent percentage on application of HEMP Process

\begin{tabular}{|l|c|c|c|}
\hline & $\begin{array}{c}\text { I do risk assessment before any } \\
\text { laboratory work. }\end{array}$ & $\begin{array}{c}\text { I conduct hazard analysis } \\
\text { before conducting my } \\
\text { research. }\end{array}$ & $\begin{array}{c}\text { During work group, we routinely } \\
\text { identify and manage risk as part of } \\
\text { our work processes. }\end{array}$ \\
\hline Strongly Disagree & $3.2 \%$ & - & - \\
Disagree & $12.9 \%$ & $6.5 \%$ & $16.1 \%$ \\
Moderate & $16.1 \%$ & $38.7 \%$ & $16.1 \%$ \\
Agree & $51.6 \%$ & $38.7 \%$ & $48.4 \%$ \\
Strongly Agree & $16.1 \%$ & $16.1 \%$ & $19.4 \%$ \\
\hline
\end{tabular}


Table 4 shows the respondent percentage on the preparedness or measures taken before conducting laboratory works. From the results shown in Table 4, 83.9\% of the respondents will inform their supervisor before using any dangerous substances in the laboratory, $12.9 \%$ respondents neither agree nor disagree, and a small percentage of respondent did not inform their supervisor, which accounts for 3.2\%. High percentage of respondents show that they are fully confident in performing the repeated experiment in the laboratory, which account for $87.1 \%$ of the total respondents. In term of discussing new experiment with their supervisors, there are only $74.2 \%$ of the respondents who prefer to do so whereas $25.8 \%$ neither agree nor disagree. This shows that there are still some of the laboratories users who prefer to do their task ahead of time before consulting with their supervisor regarding the experiments and the safety aspects that involve in the experiment.

Table 4 Respondent percentage on preparedness before laboratory works

\begin{tabular}{|l|c|c|c|c|}
\hline & $\begin{array}{c}\text { I inform my supervisor } \\
\text { before I use } \\
\text { dangerous substances } \\
\text { in the laboratory. } \\
\text { (extremely flammable, } \\
\text { explosive, etc) }\end{array}$ & $\begin{array}{c}\text { I am fully confident } \\
\text { when I perform an } \\
\text { experiment that } \\
\text { have already been } \\
\text { done several times } \\
\text { in the laboratory. }\end{array}$ & $\begin{array}{c}\text { I discuss with my } \\
\text { supervisor about } \\
\text { new experiments } \\
\text { systematically and } \\
\text { include all the } \\
\text { safety aspects. }\end{array}$ & $\begin{array}{c}\text { MSDS of each } \\
\text { reagents or chemicals } \\
\text { are available in the } \\
\text { laboratory. }\end{array}$ \\
\hline $\begin{array}{l}\text { Strongly Disagree } \\
\text { Disagree }\end{array}$ & - & - & - & - \\
Moderate & $3.2 \%$ & - & $25.8 \%$ & - \\
Agree & $12.9 \%$ & $12.9 \%$ & $45.2 \%$ & $32.3 \%$ \\
Strongly Agree & $45.2 \%$ & $51.6 \%$ & $29.0 \%$ & $45.2 \%$ \\
\hline
\end{tabular}

Figure 5 shows the rating distribution of each safety dimension in Element 2. Based on the bar chart illustrated in Figure 5, majority of the safety dimensions score rating below 4.0, especially on the application of HEMP process, which included identifying and managing risk, as well as conducting hazard analysis and risk assessment. This shows that there are still several laboratory users who do not practice hazard identification and risk assessment in their routine activity. As overall, the safety dimension for hazard and effect management process in element 2 scores a mean value of $\mu=3.91$ which falls under calculative culture. This shows that the application of hazard identification and risk assessment among laboratories users is relatively low.

Apart from that, further findings from the audit report shows that the faculty has put in place some programs with regards to improving their safety cultures. For instances, the faculty has planned to conduct a HIRARC training according to the yearly activity planning FY2019. However, it was not being organized throughout the year. 


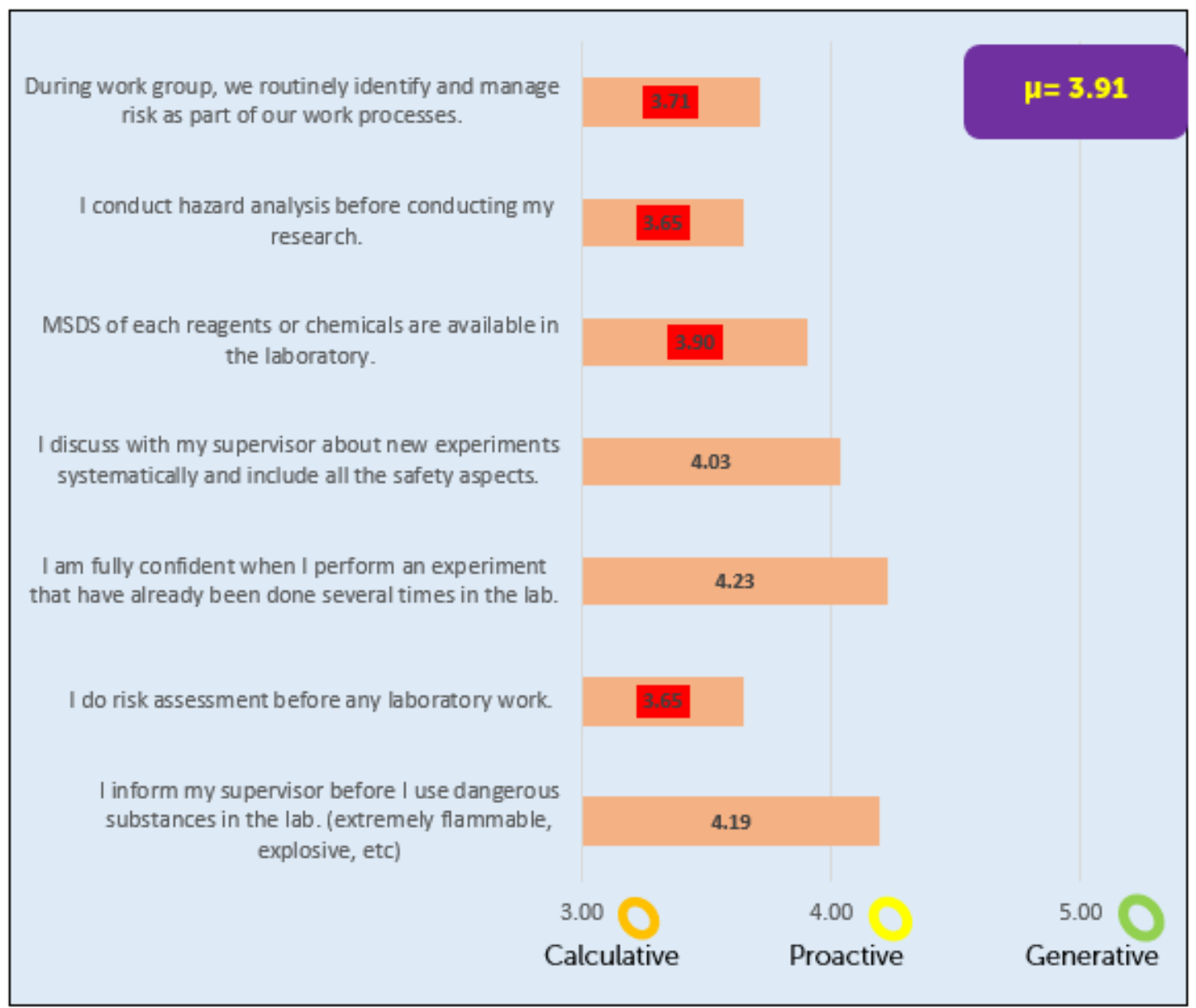

Figure 5 Rating Distribution and Safety Culture Stage for Hazard and Effect Management Process in Element 2

\section{3}

Element 3-Promoting and Communicating Safety

Figure 6 shows the third element in safety culture which is promoting and communicating safety. Promoting and communicating safety is one of the ways that can be used to influence those around us in practicing good safety culture. The seven (7) safety dimensions in Figure 6 shows the measures on how the faculty promotes and communicates safety. By referring to the bar chart in Figure 6, a total of $58.1 \%$ respondents conform that the faculty shares information regarding safety through safety newsletter or weekly bulletin, whereas $6.5 \%$ respondents disagree, and $35.5 \%$ respondents neither agree nor disagree.

As a measure to promote safety, the faculty frequently organized safety seminars to discuss safety issues and there are $58.1 \%$ of respondent who agree on it. About $70.9 \%$ of the respondents also agree that the faculty management takes part in safety walkabout at the laboratory. This is one of the ways for the management to understand the condition of the laboratory and to propose actions for the improvement of the laboratory condition. It also portrays a sense of responsibility that safety is also one of the priorities at the faculty.

Other than that, the survey also shows that students or researchers are free to share their safety concern to the faculty's management, of which $83.9 \%$ of the respondents agreed on. However, there are also a minority of respondents who felt the opposite which accounts for $6.4 \%$ of the respondents, whereas $9.7 \%$ of the respondents neither agree nor disagree. On top of that, about $64.5 \%$ of the respondents agreed that there is a procedure such as online form or suggestion box in placed for soliciting suggestions for improving safety, but a minority of respondents also felt the opposite which accounts for $6.4 \%$ of the respondents.

There are also other measures in term of non-verbal communications that the faculty used to promote and communicate safety. Examples of non-verbal communications that are available are through the display of printed information sheets about safety which is agreed by $90.4 \%$ of the respondents and $96.8 \%$ of the respondents agreed that there are safety signs available in the laboratory. About $84 \%$ of the total respondents acknowledged that the students or researchers are free to share their safety concern to the faculty management and this is also being reflected in the overall rating distribution which shows that it is one of the proactive action that the faculty made in promoting and communicating safety. 


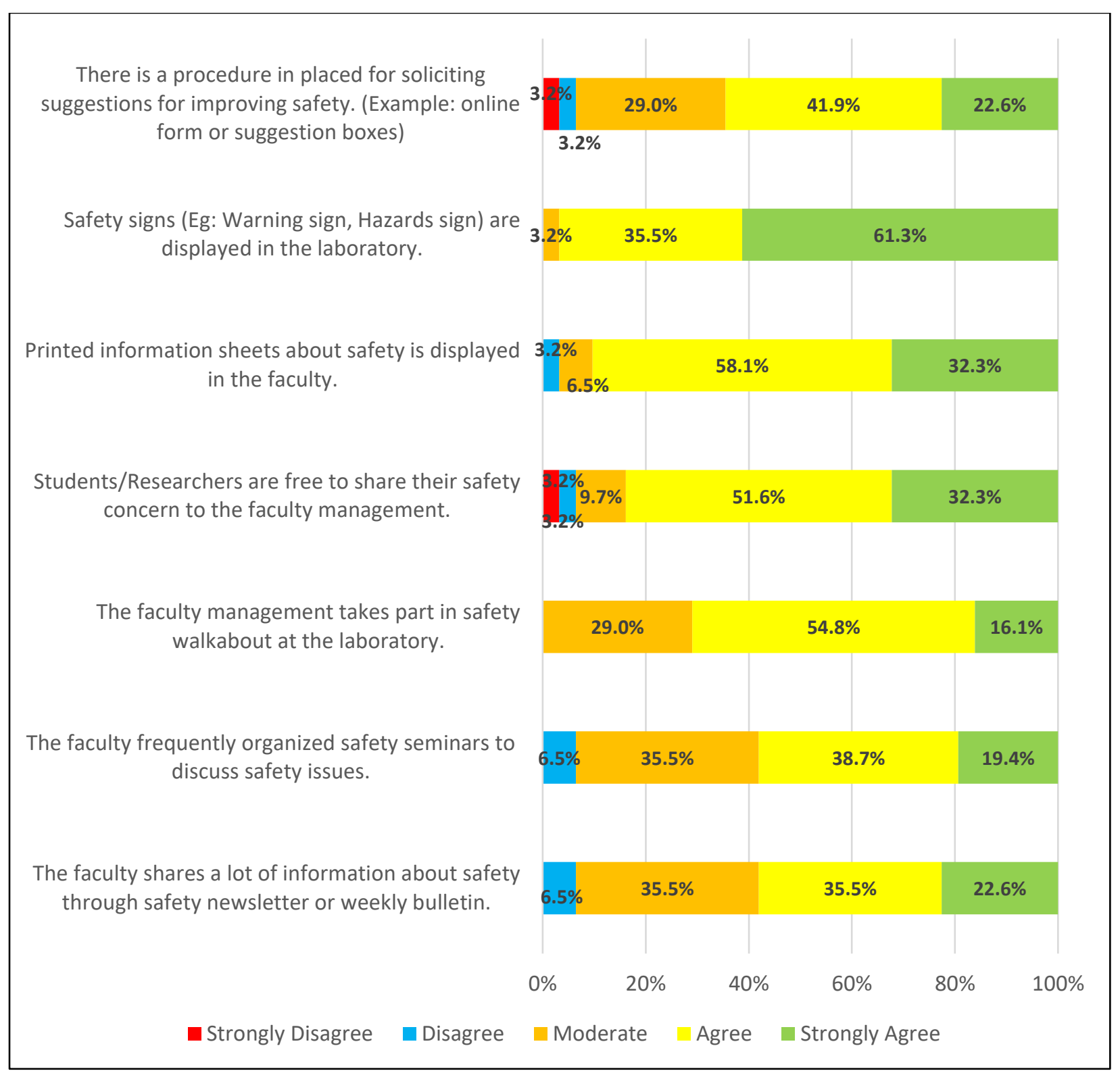

Figure 6 Rating Distribution and Safety Culture Stage for Promoting and Communicating Safety in Element 3

Based on Figure 7 which shows the rating distribution for Promoting and Communicating Safety in Element 3, the mean score obtained for this element is $\mu=3.99$ which falls under calculative safety culture. It is observed that the faculty has their own initiative in spreading safety alert among the member of faculty, however, from the survey, it also shows that there are some respondents who were not aware of these initiatives (i.e.: seminars, safety newsletter or weekly bulletin). Perhaps, the faculty could look into how to strengthen the initiative that has already been implemented and how to engage the people of the faculty to share their concern on safety as well as encouraging the member of faculty to participate more in giving feedbacks or suggestions for improving safety at the faculty, either it is in the classroom, laboratories, or within the faculty compound. 


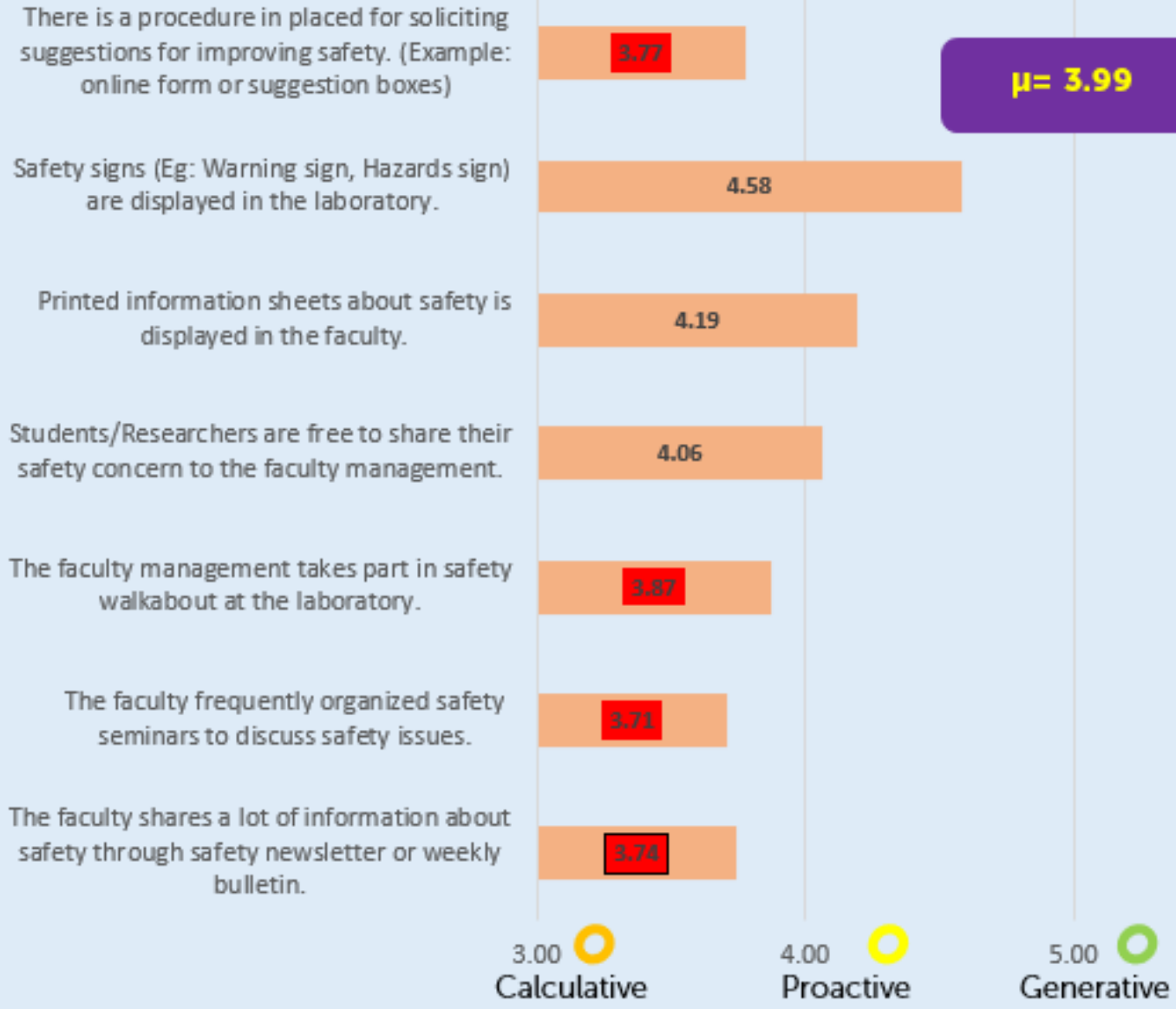

Safety signs (Eg: Warning sign, Hazards sign) are displayed in the laboratory.

Printed information sheets about safety is displayed in the faculty.

\subsection{9}

Students/Researchers are free to share their

safety concern to the faculty management.

The faculty management takes part in safety walkabout at the laboratory.

The faculty frequently organized safety seminars to discuss safety issues.

The faculty shares a lot of information about safety through safety newsletter or weekly bulletin.

5.00

Calculative

Proactive

Generative

Figure 7 Rating Distribution and Safety Culture Stage for Promoting and Communicating Safety in Element 3

\section{4}

\section{Element 4-Competency and Training}

Figure 8 shows the bar chart result for Competency and Training in Element 4 of the safety culture. Competency and training are one the most important elements because if there is an inadequate safety education and training, this can be one of the barriers that may prevent building and maintaining a strong and positive safety culture. From the bar chart shown in Figure 8, majority of the respondents which is of $96.8 \%$ of the respondents said that they fully understand the health and safety risks associated with the work for which they are responsible for in the laboratory, and the same percentage of respondents, which accounts for $87.1 \%$ agreed that they understand the safety rules for their job in the laboratory and mentioned that there is training being provided in a manner that helps them to understand how to perform their work safely in the laboratory.

Based on Figure 8, it is observed that $80.6 \%$ of the respondents had been encouraged by their supervisors to participate in a training session, with a minority of $6.5 \%$ disagree, and $12.9 \%$ neither agree nor disagree. About $71 \%$ of the respondents mentioned that they have received the training necessary to perform their job in the laboratory and the remaining 29\% neither agree nor disagree. Apart from that, $71 \%$ of the respondents are willingly to participate in safety training sessions to acquire new skills but a minority of $6.4 \%$ of the respondents is not willing to participate in safety training and the remaining $22.6 \%$ respondents neither agree nor disagree. One of the reasons that could have caused some of the respondents to feel reluctant to join in safety training is because safety training usually takes up at least two sessions which is more than a day to be completed and some perceived it as a waste of time.

Other than that, about $62 \%$ of the respondents conform that there is training on hazard recognition for those working in the laboratory whereas $35 \%$ neither agree nor disagree on it. There were also who disagree that there was training on hazard recognition available which accounts for $3 \%$ of the respondents. 


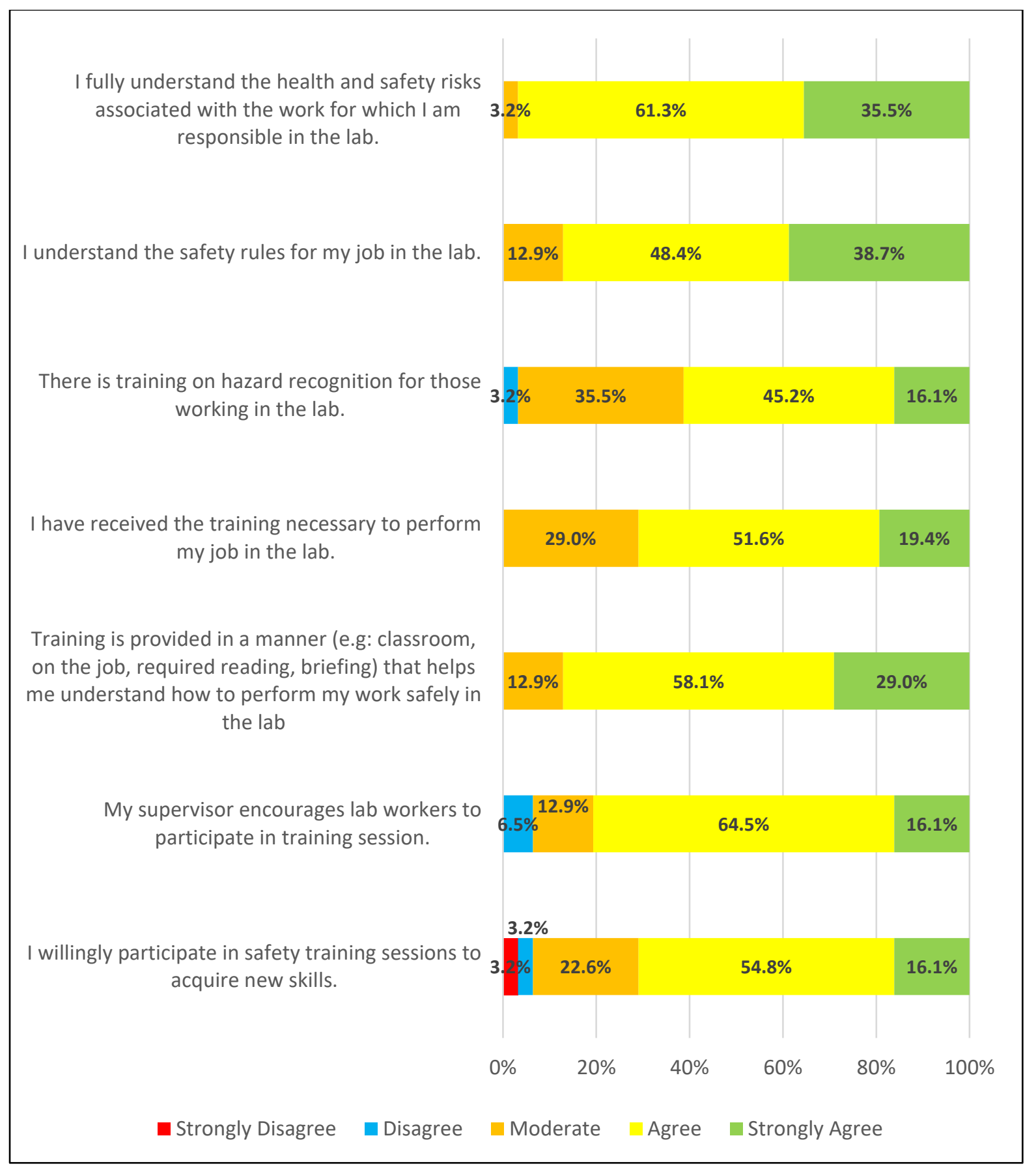

Figure 8. Respondent for Competency and Training in Element 4

Based on Figure 9 which shows the rating distribution for Competency and Training in Element 4, it can be concluded that majority of the respondents show that they have acquires the necessary skills and trainings that enables them to be eligible working in the laboratories. According to the bar chart shown in Figure 9, the organization scores considerably high for most of the sub-elements. However, there are also safety dimensions that scores below 4.0 of which related to the participation of respondents in safety training. Improvement should be focusing on the availability of training session on hazard recognition for those working in the lab and to make safety training session compulsory to those working in the laboratory. As overall, the mean score for competency and training is $\mu=4.01$ which falls under proactive safety culture. This shows that the faculty is making a good initiative in providing training and ensuring that the members of the faculty especially those working in the laboratories are equipped with the required skills and are competent prior to conducting their research or experiments in the laboratories. 


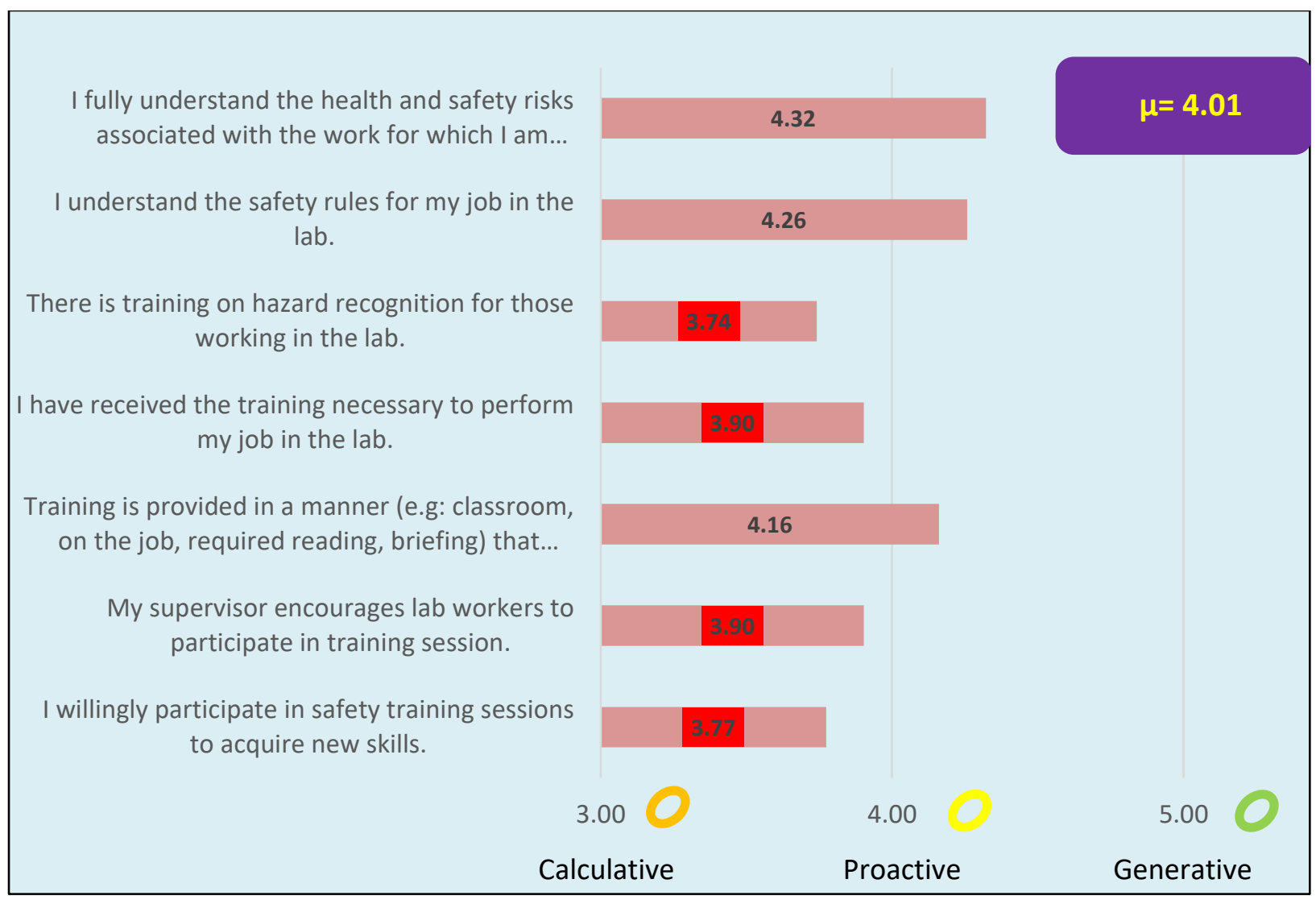

Figure 9 Rating Distribution and Safety Culture Stage for Competency and Training in Element 4

Figure 10 shows the result of respondent for Safety Implementation and Monitoring in Element 5. From the bar chart, $94 \%$ of the respondents show that they report any hazards and unsafe act whenever they encountered such situation, whereas the remaining $6.5 \%$ of the respondents neither agree nor disagree. About half of the total respondents, which accounts for $51.6 \%$ of the respondents conform that there is a systematic incident reporting system to report incident happened in the laboratory and about the same percentage of respondents have the access to the safety records in the laboratory. From the survey, there are $67.8 \%$ of the respondents actively access and use the information generated by the incident report in their daily work. There are $58.1 \%$ of the respondents mentioned that the information on recurring causes of incidents are effectively disseminated to all personnel. As for the incident investigation, there is a high percentage of respondents, which accounts for $77.4 \%$ respondents agreed that the main reason of incident investigation is to determine the root cause of the incident. 
I have access to the records regarding the safety of my laboratory.

There is a systematic incident reporting system that I can used to report any incident happened in the lab.

Information on recurring causes of incidents are effectively disseminated to all personnel.

Incident investigations are mainly used to determine root cause.

Management tracks all the recommendations from the incident reports until it is implemented.

Everyone actively accesses and use the information generated by the incident reports in their daily work.

Hazards and unsafe act will be reported whenever I encountered them.

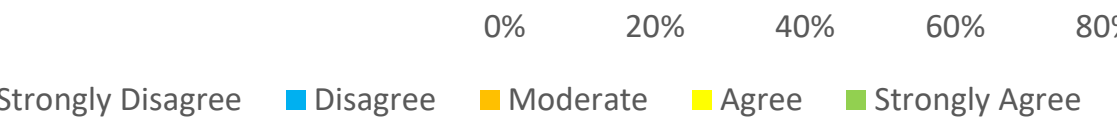

Figure 10 Respondent for Safety Implementation and Monitoring in Element 5

Figure 11 shows the rating distribution for Safety Implementation and Monitoring in Element 5. From the figure, the organization shows a proactive culture in term of hazard reporting and incident investigation, whereas the remaining safety dimensions related to incident reporting system are in the calculative stage. This shows that there is a need for improvement in term of incident reporting system and the access of this reporting system among students and member of the faculty. Example of an alternative that the faculty can do is by ensuring that records regarding the safety of the laboratory are accessible for those working in laboratories to give awareness to laboratory users of what has been happening in the laboratory or accident that is prone to happen in the laboratory. In this way, the laboratory users will be more careful and taking more safety precautions to ensure safe working at all time. Overall, the mean score for safety implementation and monitoring is $\mu=3.91$ which falls under calculative safety culture. 


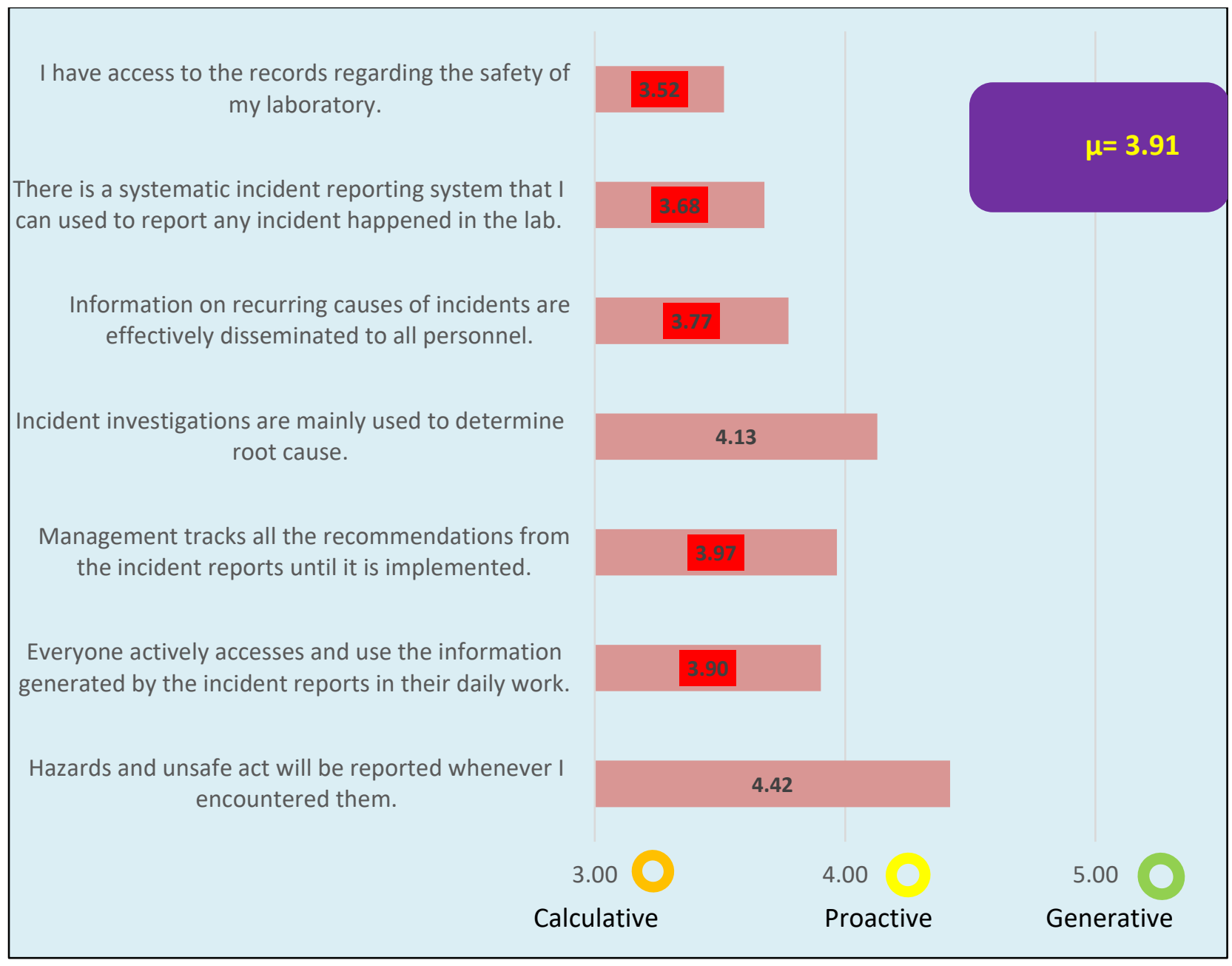

Figure 11 Rating Distribution and Safety Culture Stage for Safety Implementation and Monitoring in Element 5

Figure 12 shows the last element of safety culture in this study which is on the safety ethic and awareness. This element is essential in making sure that a positive safety culture is inculcated in every individual and it requires a continuous longterm effort. Based on the bar chart in Figure 12, there are about $90 \%$ of the respondents mostly agree that safety is an integral part of what one does. This shows that the respondents prioritize safety aspects when conducting their work in the laboratories and making sure that they work safely all the time. About $94 \%$ of the respondents show that they encourage their co-workers to be safe and this proves that those working in the laboratory not only care about themselves, but also those surrounding them.

In addition, the respondents also show good example and responsibilities in keeping their work equipment in safe working condition which accounts for $90 \%$ of the respondents and $94 \%$ of the respondents also keep their work area clean. This clearly show that the respondents follow the appropriate safety practices in the laboratory and about $81 \%$ of the respondents handle all situation as if there is a possibility of having an accident. This is important as this avoid them from being complacent at all time whenever they are in the laboratories.

About $84 \%$ of the respondents feel that the overall safety in the laboratory could be improved. This is agreeable as there are also those working in the laboratory who tends to be taking shortcuts in order to get the job done faster which accounts for about $39 \%$ of the respondents and there are some of the respondents who still overlook safety procedure in order to get job their job done faster which accounts for $29 \%$ of the respondents. 


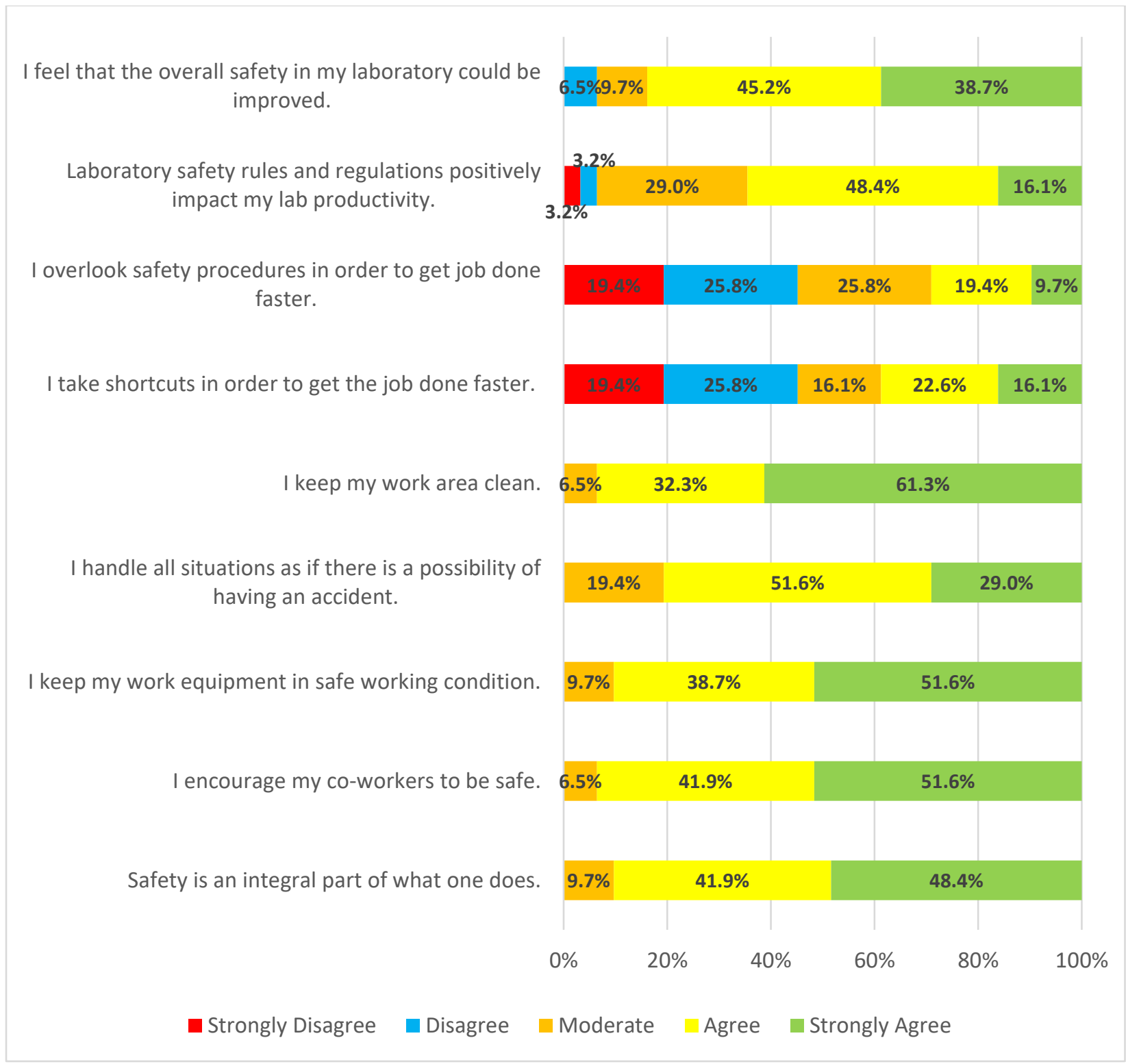

Figure 12 Respondent for Safety Ethic and Awareness in Element 6

Figure 13 shows the rating distribution for Safety Ethic and Awareness in Element 6. From the bar chart, six (6) out of nine (9) safety dimensions fall into the proactive stage whereas the remaining three (3) safety dimensions fall into calculative stage. From the result illustrated in Figure 13, it is concluded that the respondents have a good aspect in term of safety ethic and awareness although there is some part that can be improved in term of overlooking safety procedures and taking shortcuts when doing their work in the laboratory. The outcome of this study has also found out that the respondents acknowledged that the overall safety in the laboratory could be improved. As overall, the mean score for safety ethic and awareness is $\mu=4.01$ which falls under proactive safety culture. 


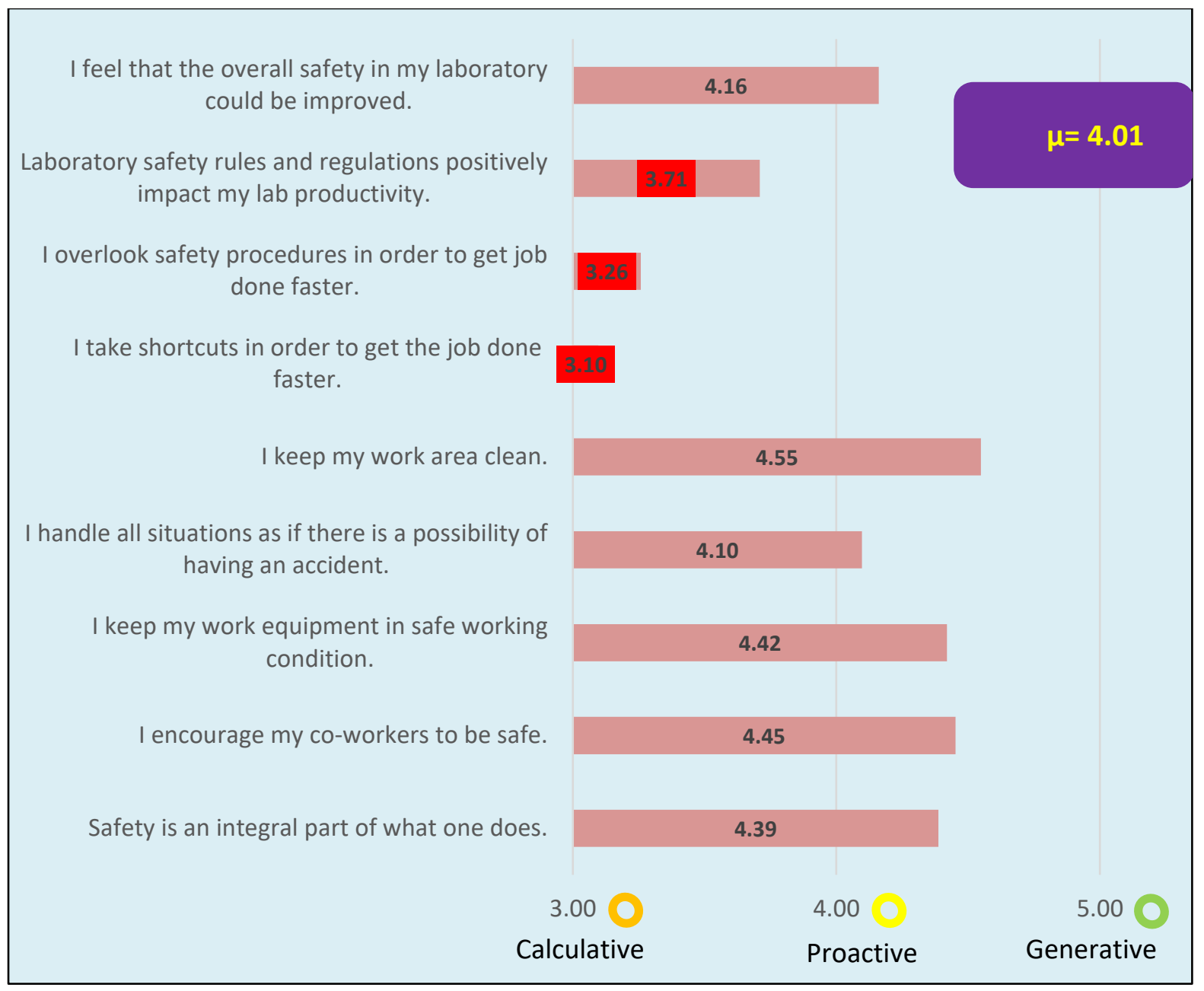

Figure 13 Rating Distribution and Safety Culture Stage for Safety Ethic and Awareness in Element 6

3.7

Overall Rating Distribution and Safety Culture Stage

The bar chart for Figure 14 shows the overall shows the overall rating distribution of each element and based on the result illustrated in the figure, it shows that the organization achieved a proactive safety culture for three (3) safety elements and the remaining three (3) falls under calculative stage. The elements that are categorized under proactive culture are leadership and commitment, competency, and training, as well as safety ethic and awareness. On the other hand, the elements that are categorized under calculative culture are hazard and effect management process, promoting and communicating safety, as well as safety implementation and monitoring. The overall score shows $\mu=3.98$, which falls under calculative. This result has suggested that the laboratories at the Faculty of Engineering still lacks a strong and positive safety culture in term of safety implementation and monitoring, promoting and communicating safety, and hazard and effect management process. 


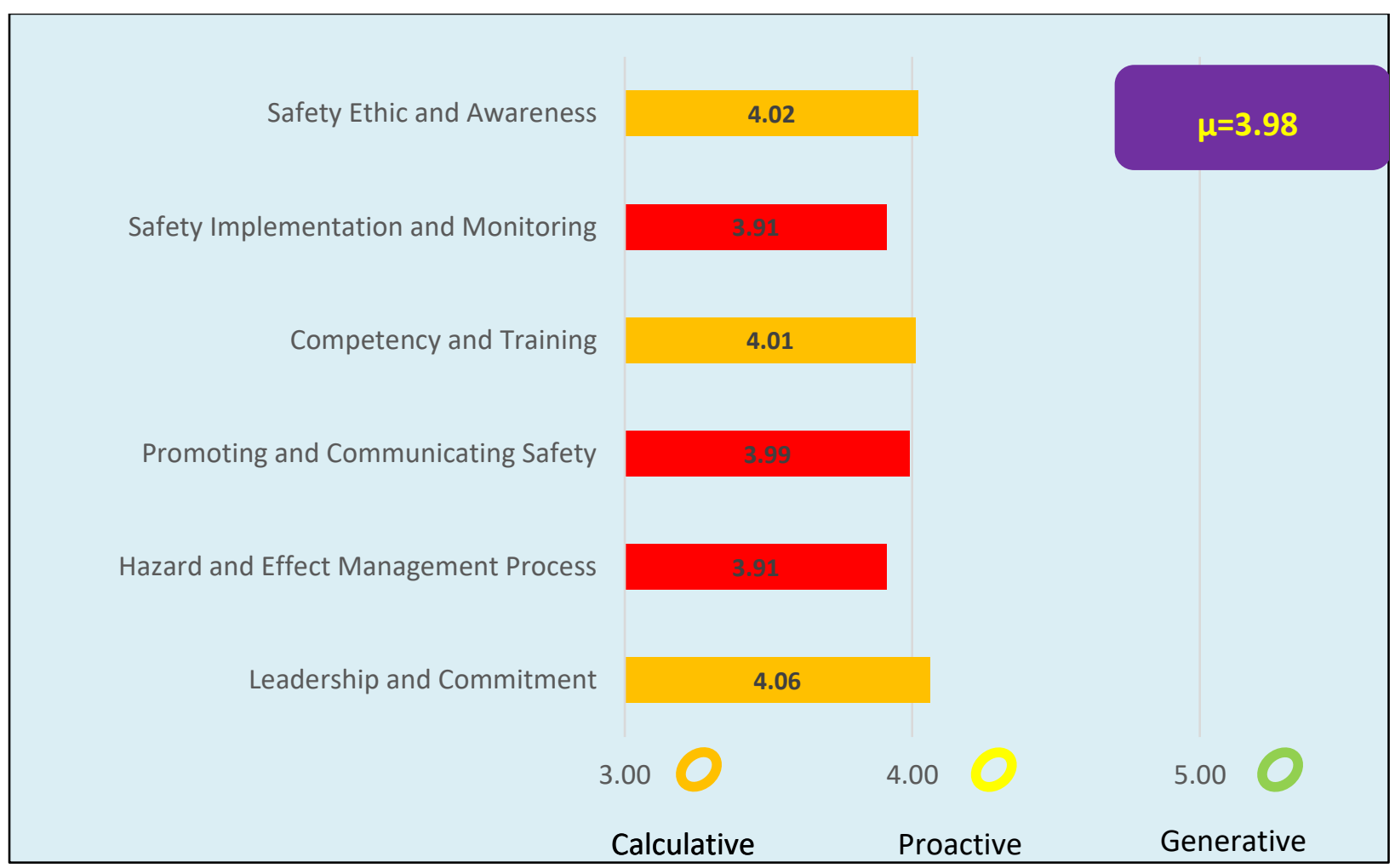

Figure 14 Overall Rating Distribution and Safety Culture Stage among Laboratory's Users at the Faculty of Engineering, UPM

\subsection{CONCLUSION}

In this project, the safety culture survey resulted in an overall score of $\mu=3.98(\mu<4.0)$ which indicates that the level of safety culture among laboratory users are in a calculative stage. According to the Hudson's theory of safety culture, calculative safety culture is a culture whereby safety is driven by the management systems. This means that the organization may have well developed procedures to manage safety, however, among the workforce, safety is not one of the values the employees sought after. Therefore, strong leadership should be taken at all levels of the academic institution in addressing not only the technical and engineering aspects of safety, but also the psychological, social, and organizational processes involved in causing injury events to further improve and strengthen the safety culture.

For future work, it is recommended that the study will involve a bigger pool of respondents from various academic organization and to have interview conducted with the OSH committee at the faculty to have an in-depth understanding and knowledge on how safety is being managed.

\section{Acknowledgements}

The authors would like to thank the members of Department of Chemical and Environmental Engineering, Process Safety and Loss Prevention Programme, Safety Engineering Interest Group (SEIG), Faculty of Engineering, Universiti Putra Malaysia, and to the respondents for the cooperation given during data collections.

\section{References}

[1] Wu, T. C., Liu, C. W., \& Lu, M. C. (2007). Safety climate in university and college laboratories: Impact of organizational and individual factors. Journal of Safety Research. 38(1): 91-102. https://doi.org/10.1016/j.jsr.2007.01.003

[2] Meyer, T. (2017). Towards the implementation of a safety education program in a teaching and research institution. Education for Chemical Engineers, 18: 2-10. https://doi.org/10.1016/j.ece.2015.06.003

[3] Shariff, A. M., \& Norazahar, N. (2012). At-risk behaviour analysis and improvement study in an academic laboratory. Safety Science, 50(1), 29-38. https://doi.org/10.1016/j.ssci.2011.06.008

[4] Kemsley, J. N. (2009). Learning From UCLA. Chemical \& Engineering News. [online] Available at: https://cen.acs.org/articles/87/i31/Learning-UCLA.html [Accessed 15 July 2020]

[5] Kemsley, J. N. (2010). Texas Tech Lessons. Chemical \& Engineering News. [online] Available at: https://cen.acs.org/articles/88/i34/Texas- 
Tech-Lessons.html [Accessed 15 July 2020]

[6] Langerman, N. (2014). Chemical Safety: Explosion hazard in synthesis of azidotrimethylsilane. San Diego: Chemical \& Engineering News. [online] Available at: https://cen.acs.org/articles/92/i43/Chemical-Safety-Explosion-hazard-synthesis.html [Accessed 15 July 2020]

[7] Mary, E. O. (2011). 'A TRUE TRAGEDY': Yale student asphyxiated in lathe accident at chemistry lab, medical examiner rules. New Haven: New Haven Register. [online] Available at: https://www.nhregister.com/news/article/A-TRUE-TRAGEDY-Yale-student-asphyxiated-in11579699.php [Accessed 15 July 2020]

[8] Bagla, P. (2018). One dead, three severely injured after explosion at Indian shock wave lab. New Delhi: American Association for the Advancement of Science. [online] Available at: https://cen.acs.org/articles/94/i28/University-Hawaii-lab-explosion-likely.html [Accessed 15 July 2020]

[9] Kemsley, J. (2016). University of Hawaii lab explosion likely originated in electrostatic discharge. Chemical \& Engineering News. [online] Available at: https://www.sciencemag.org/news/2018/12/one-dead-three-severely-injured-after-explosion-indian-shock-wave-lab [Accessed 15 July 2020]

[10] Gutiérrez, J. M., Emery, R. J., Whitehead, L. W., \& Felknor, S. A. (2013). A means for measuring safety climate in the university work setting. Journal of Chemical Health and Safety. 20(6): 2-11. https://doi.org/10.1016/j.jchas.2013.07.001

[11] Schulz, W. G. (2005). Fighting lab fires: Explosion and fire at an Ohio State University chemistry lab highlight safety issues in academia. Chemical \& Engineering News, 83(21), 34-35, [online] Available at: https://www.ehs.ucsb.edu/files/docs/ls/Ohio_fire.pdf [Accessed 15 July 2020]

[12] Abdul Aziz, H., Mohd Shari, A., Zawiyah, P. S., \& Rusli, R. (2014). Managing Operating Procedures in Process Plant for Safe Operation. Journal of Applied Sciences, 14(15), 1743-1749. https://doi.org/10.3923/jas.2014.1743.1749

[13] Banderly, B.L., (2009). Taken for granted: The burning question of laboratory safety. American Association for the Advancement of Science. American Association for the Advancement of Science. All Rights Reserved, Washington, DC.

[14] American Chemical Society (2012). Creating Safety Cultures In Academic Institutions: A Report of The Safety Culture Task Force of The ACS Committee on Chemical Safety. First Edition. All Rights Reserved, Washington, DC.

[15] Yule, S., Flin, R., \& Murdy, A. (2007). The role of management and safety climate in preventing risk-taking at work. International Journal of Risk Assessment and Management. 7(2): 137-151. https://doi.org/10.1504/IJRAM.2007.011727

[16] Collinson, David. (1999). 'Surviving the Rigs': Safety and Surveillance on North Sea Oil Installations. Organization Studies. 20(4), 579-600. DOI: $10.1177 / 0170840699204003$.

[17] IAEA (International Atomic Energy Agency), A. (2002). Safety culture in nuclear installations. (IAEA-TECDOC-1329). [online] Available at: https://www-pub.iaea.org/MTCD/Publications/PDF/te_1329_web.pdf [Accessed 15 July 2020]

[18] Kennedy, R., \& Kirwan, B. (1998). Development of a Hazard and Operability-based method for identifying safety management vulnerabilities in high risk systems. Journal of Loss Prevention in the Process Industries, 54(1): 249-274. https://doi.org/10.1016/j.jhazmat.2008.10.082

[19] Hale, A. R. (2000). Culture's confusions. Safety Science. 34(1-3): 1-14. https://doi.org/10.1016/S0925-7535(00)00003-5

[20] Glendon, A. I., \& Stanton, N. A. (2000). Perspectives on Safety Culture. Safety Science. 34(26): 193-214. https://doi.org/10.1016/S09257535(00)00013-8

[21] Cox, S. J., \& Cheyne, A. J. T. (2000). Assessing safety culture in offshore environments. Safety Science. 34: 111-129. https://doi.org/10.1016/S0925-7535(00)00009-6.

[22] Cooper, M. D., (2000). Towards a model of safety culture. Safety Science. 36: 111-136. https://doi.org/10.1016/S0925-7535(00)00035-7

[23] Health and Safety Executive. (1997). The Health and Safety Climate Survey Tool: HSE. [online] Available at: https://www.hse.gov.uk/research/rrpdf/rr042.pdf [Accessed 15 July 2020]

[24] Mod Ali, N. (2008). Challenges in promoting radiation safety culture. Journal of Nuclear Science and Technology, 45(March): 623-626. https://doi.org/10.1080/00223131.2008.10875932

[25] Energy Institute (n.d.). Hearts \& Minds. Retrieved August 4, 2020, from Energy Institute: https://heartsandminds.energyinst.org/userarea/understanding-your-culture.

[26] Hudson, P. (2007). Implementing a safety culture in a major multi-national. Safety Science. 45(6): 697-722. https://doi.org/10.1016/j.ssci.2007.04.005

[27] Beeri Tamar. (2019). The Jerusalem Post. Israel News. [online] Available at: https://www.jpost.com/israel-news/technion-professor-ofmaterials-engineering-dies-from-lab-explosion-605858 [Assessed 23 October 2020]

[28] Wiegmann, D.A., Zhang, H., von Thaden, T.L., Sharma, G., \& Giboons, A. M. (2004). Safety Culture: An Integrative Review. The International Journal of Aviation Psychology 14(2) 117-134. https://doi.org/10.1207/s15327108ijap1402_1

[29] Mearns, K., Whitaker, S. M., \& Flin, R. (2003). Safety climate, safety management practice and safety performance in offshore environments. Safety Science. 41(8): 641-680. https://doi.org/10.1016/S0925-7535(02)00011-5

[30] Choudhry, R. M., Fang, D., \& Mohamed, S. (2007). Developing a Model of Construction Safety Culture. October, $207-212$. https://doi.org/10.1061/(ASCE)0742-597X(2007)23:4(207). 